\title{
A multicentre randomised trial comparing octreotide and injection sclerotherapy in the management and outcome of acute variceal haemorrhage
}

University

Department of

Surgery, Royal

Liverpool University

Hospital

S A Jenkins

R Shields

A N Kingsnorth

R Sutton

Hepatobiliary and

Liver Transplant Unit, The Queen Elizabeth

Hospital, Birmingham $M$ Davies

E Elias

Department of Medicine, Freeman Hospital,

Newcastle-upon-Tyne

A J Turnbull

M F Bassendine

O F W James

University

Department of

Medicine,

Southampton General

Hospital, UK

J P Iredale

$S \mathrm{~K}$ Vyas

M J P Arthur

Correspondence to:

Mr R Sutton, Clinical and

Cancer Trials Unit,

Department of Surgery,

University of Liverpool,

PO Box 147,

Liverpool L69 3BX, UK

Accepted for publication 2 May 1997

S A Jenkins, R Shields, M Davies, E Elias, A J Turnbull, M F Bassendine, O F W James, J P Iredale, S K Vyas, M J P Arthur, A N Kingsnorth, R Sutton

\begin{abstract}
Background-Few studies have compared vasoactive drugs with endoscopic sclerotherapy in the control of acute variceal haemorrhage. Octreotide is widely used for this purpose, but its value remains undetermined.

Aims-To compare octreotide with endoscopic sclerotherapy for acute variceal haemorrhage.

Patients-Consecutive patients with acute variceal haemorrhage.

Methods-Patients were randomised at endoscopy to receive either a 48 hour intravenous infusion of $50 \mu \mathrm{g} / \mathrm{h}$ octreotide $(n=73)$, or emergency sclerotherapy $(\mathbf{n}=77)$.

Results-Overall control of bleeding and mortality was not significantly different between octreotide ( $85 \%, 62$ patients) and sclerotherapy $(82 \%, 63$ patients) over the 48 hour trial period (relative risk of rebleeding $0.83 ; 95 \%$ confidence interval (CI) 0.38 to 1.82), irrespective of Child's grading or active bleeding at endoscopy. One major complication was observed in the sclerotherapy group (aspiration) and two in the octreotide group (pulmonary oedema, severe paralytic ileus). During 60 days of follow up there was an overall trend towards an increased mortality in the octreotide group which was not statistically significant (relative risk of dying at 60 days $1.91,95 \%$ CI 0.97 to $3.78, p=0.06$ ). Conclusions-The results of this study indicate that intravenous octreotide is as effective as injection sclerotherapy in the control of acute variceal bleeding, but further controlled trials are necessary to evaluate the safety of this treatment.

(Gut 1997; 41: 526-533)
\end{abstract}

Keywords: variceal haemorrhage; octreotide; injection sclerotherapy

Although bleeding from oesophageal varices only accounts for approximately $10 \%$ of all presentations with upper gastrointestinal haemorrhage, the attendant mortality of between 30 and $50 \%$ makes it one of the most formidable emergencies in clinical medicine. Urgent control of active bleeding and the prevention of early rebleeding are essential to pre- vent the deterioration in liver function associated with prolonged periods of haemorrhage in cirrhotic patients, which can precipitate the development of hepatic encephalopathy and hepatorenal syndrome, and a worsening of an already abnormal clotting profile. ${ }^{1-5}$ In the past 20 years numerous reports have confirmed that injection sclerotherapy is a relatively safe and effective treatment for variceal haemorrhage, bleeding being controlled by one session in $75-85 \%$ of patients. ${ }^{6}$ However, the facilities for injection sclerotherapy are not always available at the admitting hospital and, even when they are, there is an inevitable delay between admission and treatment. Furthermore, emergency sclerotherapy in actively bleeding patients carries a higher rate of complications. ${ }^{7}$ Consequently, there is need for an effective treatment to control bleeding until definitive therapy can be carried out safely, which will facilitate sclerotherapy and reduce early rebleeding.

Vasoactive drugs theoretically constitute the optimal emergency treatment for acute variceal bleeding, as they can be administered immediately the patient is admitted to hospital without specialised expertise. The ideal vasoactive drug should be effective in controlling bleeding, free from side effects necessitating withdrawal of therapy even during prolonged administration, and should not interfere with other treatments. Of the vasoactive agents currently used in control of the acute variceal bleed, somatostatin satisfies most of these criteria. Thus in the 14 randomised controlled trials reported to date on the efficacy of somatostatin in variceal haemorrhage, bleeding was stopped in $88 \%$ of patients, and did not recur over the entire trial period in $73 \%$, nor were there any major side effects necessitating withdrawal of treatment. ${ }^{8-21}$ Furthermore, in one of these trials somatostatin was as effective as injection sclerotherapy in controlling variceal haemorrhage and preventing recurrent bleeding over a five day trial period. ${ }^{19}$

Octreotide is a synthetic octapeptide of somatostatin which contains the four amino sequences responsible for the biological activity of the hormone. It has similar effects to the naturally occurring hormone on portal pressure, ${ }^{22}$ intravariceal pressure, ${ }^{23}$ and azygos blood flow, ${ }^{24}$ suggesting that it may be of value in the control of variceal bleeding, although its haemodynamic effects in cirrhotics 
TABLE 1 Clinical and demographic features of patients

\begin{tabular}{|c|c|c|}
\hline & Injection sclerotherapy $(n=77)$ & Octreotide $(n=73)$ \\
\hline Age (years) (median (range)) & $52(30-83)$ & $57(36-83)$ \\
\hline $\mathrm{M} / \mathrm{F}$ & $38 / 39$ & $47 / 27$ \\
\hline \multicolumn{3}{|l|}{ Type of bleed } \\
\hline Index bleed (first variceal bleed) & 29 & $42^{\star}$ \\
\hline \multicolumn{2}{|l|}{ Interval bleeds (second or subsequent } & 31 \\
\hline \multicolumn{3}{|l|}{ Child's grade } \\
\hline A & 11 & 12 \\
\hline B & 25 & 22 \\
\hline $\mathrm{C}$ & 41 & 39 \\
\hline \multicolumn{3}{|l|}{ Cause of portal hypertension } \\
\hline \multicolumn{3}{|l|}{ Intrahepatic } \\
\hline Alcohol & 50 & 46 \\
\hline $\mathrm{CAH}$ & 3 & 4 \\
\hline Cryptogenic & 6 & 7 \\
\hline Haemochromatosis & 0 & 2 \\
\hline Hepatitis B and C & 0 & 1 \\
\hline Sclerosing cholangitis & 6 & 3 \\
\hline PBC & 9 & 6 \\
\hline Sarcoidosis & 0 & 1 \\
\hline Unkown & 2 & 3 \\
\hline \multicolumn{3}{|l|}{ Extrahepatic } \\
\hline PVT & 1 & 0 \\
\hline
\end{tabular}

$\mathrm{CAH}$, chronic active hepatitis; PBC, primary biliary cirrhosis; PVT, portal vein thrombosis. ${ }^{\star} \mathrm{p}<0.05$.

are heterogeneous. However, at present there have only been a relatively small number of controlled trials to evaluate the efficacy of octreotide in the control of variceal bleeding ${ }^{26-29}$ and only one of these compared it with injection sclerotherapy. The aim of this study was therefore to compare octreotide with injection sclerotherapy in the control of acute variceal haemorrhage.

\section{Methods}

The trial was carried out in four hospitals: Royal Liverpool University Hospital (93 patients), Queen Elizabeth Hospital, Birmingham (30 patients), Freeman Hospital, Newcastle-upon-Tyne (14 patients), and the Southampton General Hospital (13 patients). Entry to the trial was confined to patients with an upper gastrointestinal bleed (haematemesis and/or melaena), who on admission had an endoscopically confirmed significant variceal bleed. Endoscopy was performed as soon as possible after admission and treatment com-

TABLE 2 Transfusion requirements from time of presentation to the end of the trial period (48 hours) for patients randomised to receive injection sclerotherapy or octreotide

\begin{tabular}{lll}
\hline & $\begin{array}{c}\text { Injection } \\
\text { sclerotherapy }(n=77)\end{array}$ & Octreotide $(n=73)$ \\
\hline Blood (units) & & \\
Mean (SD) & $7.5(5.2)$ & $6.9(4.4)$ \\
Median (range) & $13(6-19)$ & $10(2-20)$ \\
Colloid (units) & & \\
Mean (SD) & $5.2(5.6)$ & $4.9(4.2)$ \\
Median (range) & $6(1-4)$ & $6(1-11)$ \\
\hline
\end{tabular}

TABLE 3 Time related variables in patients randomised to either injection sclerotherapy or octreotide. Results are expressed as median (range)

\begin{tabular}{lll}
\hline & Injection sclerotherapy $(n=77)$ & Octreotide $(n=73)$ \\
\hline $\begin{array}{c}\text { Time from onset of bleed to admission to } \\
\text { trial hospital (hours) }\end{array}$ & $5(1-144)$ & $6(0-125)$ \\
$\begin{array}{c}\text { Number of patients transferred from } \\
\text { other hospitals }\end{array}$ & $28(38 \%)$ & $35(48 \%)$ \\
$\begin{array}{c}\text { Time from onset of bleed to start of } \\
\text { treatment (hours) }\end{array}$ & $23(2-63)$ & $19(2-213)$ \\
$\begin{array}{c}\text { Time from admission to endoscopy to } \\
\text { start of treatment (hours) }\end{array}$ & $5(0-62)$ & $6(0-163)$ \\
\hline
\end{tabular}

menced immediately thereafter. In those patients who were not actively bleeding at endoscopy, a diagnosis of recent variceal bleeding was based on the presence of blood in the oesophagus, white nipple sign, or blood clot adherent to the varices and the absence of any other sources of upper gastrointestinal bleeding. A significant variceal bleed was defined as a systemic disturbance (heart rate greater than 100 beats per min and/or systolic blood pressure less than $100 \mathrm{~mm} \mathrm{Hg}$ requiring transfusion of blood or other intravenous fluids to restore the vital signs) or the necessity to transfuse two or more units of blood to restore the haemoglobin concentration.

Excluded from the trial were 36 patients in whom oesophageal varices were not the source of bleeding (oesophageal ulcers, oesophagitis, gastric varices, portal hypertensive gastropathy), those transferred from other hospitals with an oesophageal balloon in situ, or who had already received vasoactive drugs or injection sclerotherapy in the previous seven days.

One hundred and fifty patients satisfying the entry criteria were randomised on a $1: 1$ basis by means of a computer generated randomisation list to receive either injection sclerotherapy or intravenous octreotide using numbered sealed envelopes. To obtain approximately equal numbers of patients in each group the randomisation list was prepared in blocks of four. The time at which treatment was commenced was defined as time zero.

The study was approved by the Ethical Committees of the Royal Liverpool University Hospital, Queen Elizabeth Hospital, Birmingham, Freeman Hospital, Newcastle-uponTyne, and Southampton General Hospital. Verbal informed consent was obtained from the patients, or if they were confused and encephalopathic, from their next of kin.

\section{TREATMENT PROTOCOLS}

Injection sclerotherapy

Injection sclerotherapy was carried out using a fibreoptic endoscope during the diagnostic endoscopy. Every attempt was made to inject each varix with $2-3 \mathrm{ml}$ of ethanolamine oleate. If significant oozing persisted after completion of sclerotherapy, balloon tamponade was instituted for a maximum period of 12 hours. The need to reinsert the balloon to control persistent or recurrent bleeding constituted treatment failure.

\section{Octreotide}

Patients randomised to receive octreotide (Sandoz Pharmaceuticals Ltd) were infused intravenously with $50 \mu \mathrm{g} / \mathrm{h}$ for 48 hours from the time of initial endoscopy. If bleeding persisted after starting octreotide, balloon tamponade was instituted for a maximum period of 12 hours. Reinsertion of the balloon to control continued or recurrent variceal bleeding constituted treatment failure. All patients randomised to receive octreotide received injection sclerotherapy as soon as possible after the 48 hour trial period. 
TABLE 4 Overall control of variceal bleeding by either injection sclerotherapy or octreotide related to severity of liver disease or active bleeding at the time of entry into the study

\begin{tabular}{lll}
\hline & $\begin{array}{l}\text { Injection } \\
\text { sclerotherapy }(n=77)\end{array}$ & Octreotide $(n=73)$ \\
\hline $\begin{array}{l}\text { Overall } \\
\text { Child's grade }\end{array}$ & $63 / 77(82 \%)$ & $62 / 73(85 \%)$ \\
A & & \\
B & $8 / 11(73 \%)$ & $9 / 12(75 \%)$ \\
C & $21 / 25(84 \%)$ & $18 / 22(82 \%)$ \\
$\begin{array}{l}\text { Actively bleeding at } \\
\text { time of diagnostic }\end{array}$ & $34 / 41(83 \%)$ & $34 / 39(87 \%)$ \\
endoscopy & $38 / 49(77 \%)$ & $31 / 36(86 \%)$ \\
\hline
\end{tabular}

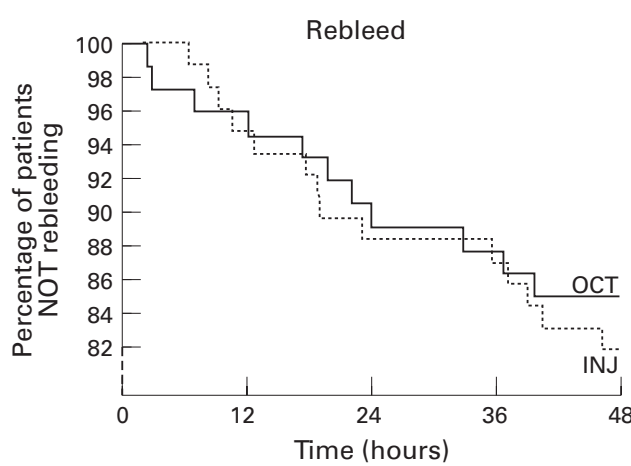

Figure 1: Kaplan-Meier plots for times to rebleeding after initiation of therapy in the sclerotherapy (INF) and octreotide (OCT) groups. Time zero indicates the commencement of therapy.

SUCCESS OF TREATMENT

Successful control of haemorrhage was defined by the absence of overt signs of bleeding and stabilisation of both vital signs and the haemoglobin concentration over the 48 hours following randomisation. Failure to control bleeding or early recurrence of bleeding was defined as haematemesis/and or melaena accompanied by either a systemic disturbance or a fall in the haemoglobin concentration requiring blood transfusion. The time of entry into the trial (zero time) and to failure of treatment were recorded. In addition, the patients were followed up for 60 days to determine any mortality.

\section{STATISTICAL ANALYSIS}

Sample size estimation was based on an expected efficacy of controlling bleeding in the two groups of $80 \%$ (based on our previous experience with one course of injection sclerotherapy and naturally occurring somatostatin). ${ }^{19}$ Confidence limits tables were used to calculate that with a total sample size of 140 patients there would be a $90 \%$ chance of detecting a $20 \%$ difference between the two treatments with a type II error of less than $10 \%$.

The efficacy of octreotide and injection sclerotherapy with respect to control of bleeding, mortality, complication rates, etc, was compared using a two tailed Fisher's exact test or $\chi^{2}$ test with Yates's correction where appropriate. In addition, the percentage differences in rebleeding and mortality between the two treatments together with the $95 \%$ confidence limits were determined. Since these calculations do not take into account the time to

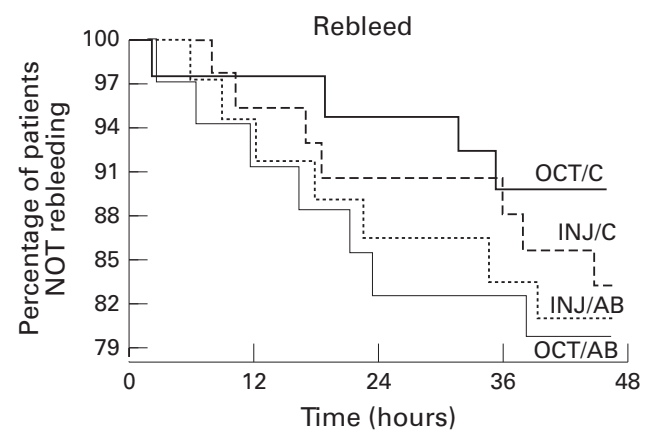

Figure 2: Kaplan-Meier plots for time to rebleeding after sclerotherapy (INF/AB) or octreotide (OCT/AB) in patients with Child's $A$ or $B$ liver diseases and in patients with Child's $C$ liver function in the sclerotherapy (INF/C) and octreotide $(O C T / C)$ groups are plotted separately.

Time zero indicates commencement of therapy.

rebleeding or death, the relative risk of rebleeding or dying in the octreotide or sclerotherapy group was calculated using Cox's proportional hazards model. ${ }^{30}$ This model was used to identify, and if necessary, adjust the relative risks for independent prognostic factors influencing both control of bleeding and mortality. Any differences in the results between centres was evaluated using a partitioning $\chi^{2}$.

\section{Results}

There was no significant difference between the four participating centres with respect to control of bleeding or mortality in patients treated with either endoscopic injection sclerotherapy or octreotide. Seventy seven patients were randomised to receive injection sclerotherapy and 73 to octreotide. Nine patients entered into the trial had received injection sclerotherapy within the previous month (range 9-28 days). There was no difference in the distribution of these patients between the injection sclerotherapy and octreotide groups. The aetiology of the portal hypertension, age, and severity of their liver disease according to Child's criteria ${ }^{31}$ was similar in the two groups (table 1). There were more men in the octreotide group and a significantly greater number of index (first) bleeds in the octreotide group ( $\chi^{2}$ with Yates's correction $=5.17, \mathrm{df}=1$, $\mathrm{p}<0.05$; table 1$)$. The number of patients actively bleeding at endoscopy in the sclerotherapy group (49/77) was greater than in the octreotide group (36/73). However, neither sex nor the type of bleed (first or recurrent variceal haemorrhage), nor the presence of active bleeding at the time of endoscopy, were independently prognostic with respect to control of bleeding or death using Cox's proportional hazards model.

Both transfusion requirements (from the time of presentation to the end of the trial period; table 2) and time related variables (time from onset of bleed to admission, number of patients transferred from other hospitals, transfer time, time from admission to start of treatment, or time from onset of bleed to start of treatment; table 3) were not significantly different between the two groups of patients. 
TABLE 5 Causes of death in patients treated with injection sclerotherapy or octreotide

\begin{tabular}{lll}
\hline & $\begin{array}{l}\text { Injection sclerotherapy } \\
(n=77)\end{array}$ & $\begin{array}{l}\text { Octreotide } \\
(n=73)\end{array}$ \\
\hline $\begin{array}{l}\text { Uncontrolled bleeding in trial period } \\
\text { Liver failure }\end{array}$ & 0 & 2 \\
$\begin{array}{l}\text { Hepatorenal syndrome } \\
\text { Multiple organ failure }\end{array}$ & 6 & 3 \\
$\begin{array}{l}\text { Recurrent variceal bleed (outside trial) } \\
\text { Rectal bleeding, severe coagulopathy, }\end{array}$ & 0 & 6 \\
$\quad 1$ & 1 & $5^{\star}$ \\
$\quad$ Cardiogenic shock following liver & 1 & 2 \\
$\quad$ transplant & 1 & 0 \\
$\begin{array}{l}\text { Anastomotic leak following oesophageal } \\
\quad \text { transection }\end{array}$ & 0 & 0 \\
$\begin{array}{l}\text { Hepatocellular carcinoma } \\
\text { Chest infection, pulmonary oedema, }\end{array} \quad 0$ & 1 \\
$\quad$ cerebral haemorrhage & 0 & 1 \\
$\begin{array}{l}\text { Respiratory arrest } \\
\text { Grand mal fit }\end{array}$ & 1 & 1 \\
Carcinoma of bronchus & 0 & 0 \\
& 0 & 1
\end{tabular}

${ }^{\star} \mathrm{p}=0.025$

TABLE 6 Overall hospital mortality and hospital mortality related to Child's grading in patients receiving injection sclerotherapy or octreotide

\begin{tabular}{lll}
\hline & $\begin{array}{l}\text { Injection } \\
\text { sclerotherapy }(n=77)\end{array}$ & Octreotide $(n=73)$ \\
\hline $\begin{array}{l}\text { Overall mortality } \\
\text { Mortality related to }\end{array}$ & $13 / 77(16.9 \%)$ & $23 / 73(31.5 \%)$ \\
$\quad$ Child's grading & & \\
A & $1 / 11(9.1 \%)$ & $0 / 12(0 \%)$ \\
B & $1 / 25(4.0 \%)$ & $6 / 22(27.2 \%)$ \\
C & $11 / 41(26.8 \%)$ & $17 / 39(43.6 \%)$ \\
\hline
\end{tabular}

INJECTION SCLEROTHERAPY

Injection sclerotherapy initially controlled or reduced bleeding in all 77 patients, of whom 20 $(26 \%)$ also required 12 hours of balloon tamponade after this procedure to control persistent oozing. Fourteen patients $(18 \%)$ in the sclerotherapy group rebled during the 48 hour trial period. Consequently, the overall control rate achieved with injection sclerotherapy alone or with immediate tamponade as an adjunct was $82 \%$ and 50 of these patients were discharged from hospital and were alive 60 days after presentation. Bleeding was successfully controlled by alternative therapy in all 14 patients but one patient died of liver failure. The remaining 13 patients were discharged from hospital and all were alive 60 days after initial presentation.

\section{OCTREOTIDE}

Octreotide successfully controlled bleeding in all 73 patients but $13(18 \%)$ required 12 hours of balloon tamponade as an adjunct to control persistent bleeding immediately after the commencement of therapy. Eleven patients rebled during the 48 hour trial period so that overall control of bleeding in the octreotide group was $85 \% ; 40$ of these were discharged from hospital with 39 still alive 60 days after presentation. Rebleeding was controlled by alternative therapies in nine of 11 patients but two patients died following recurrent uncontrollable haemorrhage. Of the remaining nine patients who rebled in the octreotide group, eight were discharged from hospital and were still alive 60 days after their initial presentation. The other patient died from progressive hepatic and renal failure without any further recurrent bleeding.

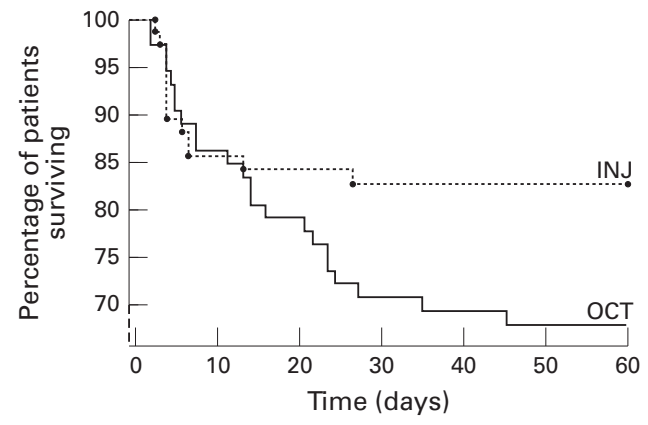

Figure 3: Kaplan-Meier survival plots for patients randomised to receive injection sclerotherapy (INF) or octreotide (OCT). Time zero indicates the commencement of therapy.

The median time from randomisation to injection sclerotherapy in the octreotide group was 48 hours (range 11-107 hours).

COMPARISON OF REBLEEDING BETWEEN TREATMENTS

The overall control of bleeding (cessation of haemorrhage and no rebleeding) during the 48 hour trial period was not statistically significant between the octreotide and sclerotherapy groups, irrespective of either Child's grade or the presence of active bleeding at the time of endoscopy (table 4). The Kaplan-Meier plots for rebleeding (fig 1) were therefore very similar for both groups. The estimated difference in rebleeding rates between patients receiving octreotide and injection sclerotherapy was 3\%. However, the $95 \%$ confidence limits indicate that the rebleeding rate in the octreotide group could be $15 \%$ less or $9 \%$ more than in the sclerotherapy group.

Using Cox's proportional hazards model the relative risk of rebleeding in the octreotide group was 0.83 times less than in the sclerotherapy group. However, the $95 \%$ confidence limits indicate that the relative risk of rebleeding in the octreotide group compared with patients receiving sclerotherapy could be as low as 0.38 or as high as 1.82 . No prognostic factor, including the severity of the liver disease (fig 2), was independently associated with the relative risk of rebleeding.

\section{COMPARISON OF MORTALITY BETWEEN} TREATMENTS

The main causes of death in both groups were liver failure, hepatorenal syndrome, and multiple organ failure (table 5). The number of patients dying from multiple organ failure (hepatic, renal, and pulmonary) was significantly higher in the octreotide group (Fisher's exact test, $p=0.025$ ) compared with the sclerotherapy group. However, overall, there was no significant difference in the mortality between the groups as a whole or when related to the severity of hepatic dysfunction (table 6).

The Kaplan-Meier plots of the survival curves over the first 60 days for patients treated with either therapy indicated that most deaths occurred within the first 15 days (fig 3). Furthermore, death was mostly associated with severe liver disease (fig 4). Table 7 shows the relative risk of dying at various times after 


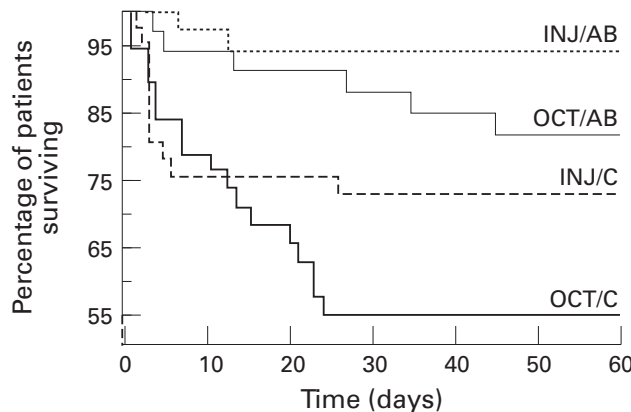

Figure 4: Kaplan-Meier survival plots for patients with $C$ Child's $A$ and $B$ liver disease randomised to receive sclerotherapy (INF/AB) or octreotide (OCT/AB). The survival of patients with severe liver disease (Child's $C$ ) in either the sclerotherapy $(I N \mathcal{H} / C)$ or octreotide $(O C T / C)$ group was plotted separately. Time zero indicates the commencement of therapy.

admission using Cox's proportional hazards model. During the first five days after admission the relative risks of dying in the two groups were similar. Thereafter, more patients died in the octreotide group so that at 60 days following admission the difference in the mortality between the two groups had almost reached statistical significance.

The degree of hepatic dysfunction (Child's grade), the presence of encephalopathy, and the plasma concentrations of albumin, bilirubin, and creatinine were all identified as being independently significant prognostic factors with respect to mortality using Cox's proportional hazards model. Not surprisingly in view of the fact that the plasma concentrations of albumin and bilirubin and the presence of encephalopathy comprise three of the five categories on which the Child's grade is based, the degree of hepatic dysfunction was also significantly prognostic with respect to mortality. Both groups of patients were well matched with respect to these independently significant prognostic factors on admission to hospital. Furthermore, there were no significant differences in the degree to which these prognostic variables deteriorated during the first four days after admission to hospital in patients treated with either octreotide or injection sclerotherapy. Consequently, the relative risk of dying in the octreotide group compared with patients treated with sclerotherapy was not altered when the independently significant prognostic factors were taken into account in the analysis.

COMPLICATIONS OF TREATMENT

The majority of complications in both groups were minor and resolved spontaneously. More

TABLE 7 Relative risk of dying in patients treated with octreotide compared with those receiving injection sclerotherapy in the first 60 days after admission

\begin{tabular}{|c|c|c|c|c|c|}
\hline $\begin{array}{l}\text { Time after } \\
\text { admission }\end{array}$ & Treatment & $\begin{array}{l}\text { Number of } \\
\text { deaths }\end{array}$ & Relative risk & $95 \% C I$ & $\begin{array}{l}\text { Statistical } \\
\text { significance }\end{array}$ \\
\hline 48 hours & $\begin{array}{l}\text { Sclerotherapy } \\
\text { Octreotide }\end{array}$ & $\begin{array}{l}2(3 \%) \\
2(3 \%)\end{array}$ & 1.07 & 0.15 to 7.57 & 0.95 \\
\hline 5 days & $\begin{array}{l}\text { Sclerotherapy } \\
\text { Octreotide }\end{array}$ & $\begin{array}{l}9(12 \%) \\
8(11 \%)\end{array}$ & 0.93 & 0.36 to 2.41 & 0.88 \\
\hline 42 days & $\begin{array}{l}\text { Sclerotherapy } \\
\text { Octreotide }\end{array}$ & $\begin{array}{l}13(17 \%) \\
22(30 \%)\end{array}$ & 1.82 & 0.92 to 2.62 & 0.09 \\
\hline 60 days & $\begin{array}{l}\text { Sclerotherapy } \\
\text { Octreotide }\end{array}$ & $\begin{array}{l}13(17 \%) \\
23(31 \%)\end{array}$ & 1.91 & 0.97 to 3.78 & 0.06 \\
\hline
\end{tabular}

CI, confidence interval.
TABLE 8 Complications associated with octreotide and injection sclerotherapy

\begin{tabular}{lll}
\hline & $\begin{array}{l}\text { Injection } \\
\text { sclerotherapy }\end{array}$ & Octreotide \\
\hline Paralytic ileus & 0 & $1^{\star}$ \\
Abdominal pain & 0 & 1 \\
Oesophageal & & 0 \\
$\quad$ ulceration & 8 & 15 \\
Hyperglycaemia & 0 & 0 \\
Pleural effusion & 1 & 1 \\
Pulmonary oedema & 0 & 0 \\
Aspiration & 1 & 0 \\
Retrosternal pain & 2 & 0 \\
Pyrexia & 2 & 1 \\
Infection & 1 & $19 / 73(26 \%)$ \\
Total & $15 / 77(19 \%)$ & \\
\hline
\end{tabular}

^Necessitated withdrawal of treatment.

complications were observed in patients treated with octreotide than in those receiving sclerotherapy (table 8) but the difference did not reach statistical significance. Hyperglycaemia was the most common complication in the octreotide group, occurring in 15 patients (duration 6-72 hours). Two patients required insulin to correct the hyperglycaemia, but the condition resolved spontaneously in the remainder. Similarly, retrosternal pain, pyrexia, and infection in the injection sclerotherapy group resolved spontaneously, and oesophageal ulceration was asymptomatic and only noted at subsequent endoscopy. However, one patient in the sclerotherapy group developed aspiration pneumonitis. In the octreotide group two patients developed severe complications, the first pulmonary oedema, and the second paralytic ileus that necessitated withdrawal of treatment.

\section{Discussion}

The efficacy of injection sclerotherapy in controlling acute variceal bleeding coupled with the relatively low morbidity and mortality associated with the procedure in major centres led to the suggestion that this treatment should be regarded as the "gold standard" against which all other therapies should be evaluated. ${ }^{32}$ However, several recent trials have shown variceal ligation to be as effective as injection sclerotherapy in the control of acute variceal haemorrhage, with fewer side effects and a reduced risk of rebleeding. ${ }^{33-36}$ Consequently variceal ligation is now emerging as the treatment of choice for acute variceal bleeding in those centres with the facilities and expertise to carry out the procedure. Nevertheless, the present study was begun before data became available on the comparative benefits of variceal ligation, thus sclerotherapy was used.

The results of this study suggest that octreotide is as effective as injection sclerotherapy in the control of variceal haemorrhage and prevention of rebleeding during the first 48 hours after admission, irrespective of the severity of the liver disease or whether the varices were actively bleeding at endoscopy. However, it should be noted that 12 hours of balloon tamponade was necessary to achieve initial haemostasis in a similar proportion of patients treated with injection sclerotherapy $(26 \%)$ or octreotide $(18 \%)$. Balloon tamponade of the oesophagus to control persistent bleeding after 
sclerotherapy is an integral component of the technique. Therefore, the need to initiate balloon tamponade for 12 hours to control persistent bleeding after completion of sclerotherapy was not considered a treatment failure. In order to avoid bias in favour of the sclerotherapy group, patients who received 12 hours of balloon tamponade to control persistent bleeding immediately after starting octreotide infusion were also not considered to be treatment failures. Without the use of adjuvant balloon tamponade, the immediate control of bleeding achieved by injection sclerotherapy and octreotide in this study would have been reduced by $26 \%$ and $18 \%$ respectively. However, as both the number of patients who required balloon tamponade to achieve initial haemostasis, and the rebleeding rates were similar in the injection sclerotherapy and octreotide groups, the overall conclusion that the two treatments are equally effective in controlling variceal haemorrhage remains unchanged. The results also suggest that octreotide, with up to 12 hours balloon tamponade to achieve initial control of bleeding when necessary, can be used in district hospitals prior to transfer to tertiary centres.

Previous randomised controlled trials of octreotide in the control of acute variceal haemorrhage have provided conflicting results. In two studies in which octreotide was infused at a rate of $25 \mu \mathrm{g} / \mathrm{h}$ for the duration of the trial (48 and 24 hours respectively), control of haemorrhage was achieved in $50 \%{ }^{26}$ and $63 \%{ }^{28}$ of patients. Silvain et al used an initial 12 hour infusion of octreotide followed by subcutaneous administration of the analogue for the remainder of their trial period ( 36 hours), and reported an overall control of bleeding in only $55 \%$ of patients. ${ }^{27}$ In contrast to these three trials, a more recent study using a 48 hour infusion of $50 \mu \mathrm{g} / \mathrm{h}$ octreotide reported a higher overall control of bleeding $(84 \%)$, results more in accord with the findings of this study. ${ }^{29} \mathrm{In}$ addition to such factors as the aetiology and severity of the liver disease, and the starting point of treatment in relation to haemorrhage, the most obvious difference which appears to influence the efficacy of octreotide is the dosing regimen. Thus a much better control rate was achieved with an infusion of $50 \mu \mathrm{g} / \mathrm{h}$ octreotide than $25 \mu \mathrm{g} / \mathrm{h}$. Possibly, the lower dose of octreotide is less effective than $50 \mu \mathrm{g} / \mathrm{h}$ in reducing collateral blood flow, including that through the varices, presumably the most important determinant in the control of variceal haemorrhage. This suggestion needs to be confirmed in a dose response study on the effects of octreotide on azygos blood flow.

The most important outcome in any treatment of acute variceal haemorrhage is survival. In this study, no significant difference in mortality was observed between the octreotide $(31 \%)$ and injection sclerotherapy (17\%) groups up to 60 days after admission. Although the mortality in the two treatment groups was almost identical up to five days after admission, thereafter more patients treated with octreotide died during follow up. This was reflected by the greater hospital and 60 day mortality in the octreotide group (30\% and $31 \%$ respectively) which was more than in patients treated with sclerotherapy ( $17 \%$ and $17 \%$ respectively). The poorer survival in the octreotide group was unexpected, as sclerotherapy was not withheld beyond the initial 48 hour trial period in this group. Therefore it seems unlikely that the increased number of late deaths during the follow up period in the octreotide group was related to the delay in sclerotherapy per se. The only other comparable study reported an appreciable, but not significantly greater 30 day mortality in patients treated with sclerotherapy (41\%) compared with those receiving octreotide $(29 \%),{ }^{29}$ a reverse finding to ours. Unfortunately, neither that trial nor our own includes sufficient numbers of patients to demonstrate whether octreotide has either a beneficial or detrimental effect on the survival of patients following a variceal bleed (power 0.95, type II error 0.05). In our study there were significantly more patients with an index bleed randomised to octreotide treatment, and although index bleeding was not independently prognostic of mortality in this study, larger studies have demonstrated that a higher mortality is associated with index, compared with recurrent, variceal haemorrhage. ${ }^{37}$ Nevertheless, a cause for concern in the present study was the finding that significantly more octreotide treated patients died of multiple organ failure than those receiving sclerotherapy. This observation requires further investigation, particularly as octreotide has been reported to have deleterious effects on the cardiovascular system ${ }^{38}{ }^{39}$ and the liver. ${ }^{40}$ Furthermore, the effects of somatostatin and octreotide on renal function in stable cirrhotics are controversial ${ }^{41-43}$ and have not been investigated in patients bleeding from oesophageal varices, the majority of whom are hypovolaemic and in the process of being resuscitated during vasoactive treatment. It is possible that octreotide exacerbates diminished perfusion of the kidneys and/or liver in patients with grossly impaired renal and/or hepatic function during the initial hypotensive period related to the bleed. This study provides no direct evidence for this suggestion, as there was no significant difference in the degree to which plasma albumin, bilirubin, and creatinine concentrations deteriorated during the first four days following treatment with either octreotide or sclerotherapy. However, an adverse effect of octreotide on the cardiovascular system ${ }^{38}{ }^{39}$ and in particular on pulmonary haemodynamics ${ }^{38}$ as being contributory to the increased number of late deaths in the octreotide treated patients cannot be discounted and requires further investigation.

In the present study more complications were associated with octreotide than injection sclerotherapy but the difference between the groups did not reach statistical significance. The majority of complications associated with octreotide or sclerotherapy were minor, and similar to those previously reported for both treatments. However, serious complications were observed in two patients in the octreotide group, namely pulmonary oedema in one and 
paralytic ileus necessitating withdrawal of treatment in the other. Similarly, one patient in the sclerotherapy group aspirated. The incidence of side effects associated with octreotide in this study is similar to that observed in some studies, ${ }^{27}{ }^{28}$ but higher than that reported in others. ${ }^{26}{ }^{29}$ Nevertheless, the safety of octreotide seems to be greater than that reported for other stop gap treatments used in the control of acute variceal haemorrhage, such as balloon tamponade, ${ }^{44}$ vasopressin, ${ }^{46}{ }^{47}$ vasopressin with nitroglycerin, ${ }^{48-50}$ and glypressin. ${ }^{51-53}$

In conclusion, octreotide seems to be a very effective treatment for the control of variceal bleeding and has few side effects, although in $18 \%$ balloon tamponade was necessary as an adjuvant (a similar proportion to patients treated with sclerotherapy). Octreotide may therefore be a valuable means of controlling severe variceal bleeding allowing later definitive treatment under optimal conditions. However, in view of the trend towards an increased mortality coupled with a significantly greater number of patients dying from multiple organ failure in the octreotide group, further controlled trials are required to tackle these points in patients who are hypovolaemic because of bleeding varices and are being resuscitated, before the drug can be recommended for general use.

This work was supported by a grant from Sandoz Pharmaceuticals Ltd, Camberley, UK. We are grateful to Mr F Kendall, Biometrics Department, Sandoz Pharmaceuticals, Camberley, UK, for carrying out the statistical analysis and to the junior medical staff and nurses in the four participating hospitals who helped in the care of the patients.

1 McCormick PA, Kaye GL, Greenslade L, Cardin F, Hobbs $\mathrm{KEF}$, Burroughs AK. Esophageal staple transection as a salvage procedure after failure of acute sclerotherapy. Hepatology 1992; 15: 403-6.

2 Sarin SK, Sachdev G, Nanda R, Batra SK, Anand BS. Comparison of two time schedules for endoscopic sclerotherapy: a prospective randomised controlled trial. Gut 1986; 18: 710-3.

3 Fessel JM, Conn HO. An analysis of the causes and prevention of hepatic coma [abstract]. Gastroenterology 1972; 62: A191.

4 Conn HO. The hepatic encephalopathies. In: Conn HO, Bircher J, eds. Hepatic encephalopathy: management with lac-
tulose and related carbohydrates. East Lansing, MI: Medi-Ed tulose and related carb

5 Gines A, Escorsell A, Gines P, Salo J, Jimenez W, Ingladal L, et al. Incidence, predictive factors and prognosis of hepatorenal syndrome in cirrhosis with ascites. Gastroenterology 1993; 105: 229-36.

6 Terblanche J, Burroughs AK, Hobbs KEF. Controversies in the management of bleeding oesophageal varices. $N$ Engl $f$ Med 1989; 320: 1393-8.

7 Zambelli A, Acridiacono PG, Acridiacono R. Complications of endoscopic variceal sclerotherapy (ESV): a multicentre study of 1192 patients [abstract]. Gastroenterology 1993; 104: A1023.

8 Kravetz D, Bosch J, Teres J, Bruix J, Rimola A, Rodes J. Comparison of intravenous somatostatin and vasopressin infusions in treatment of acute variceal haemorrhage. infusions in treatment of

9 Jenkins SA, Baxter JN, Corbett W, Devitt P, Ware J, Shields R. A prospective randomised controlled trial comparing somatostatin and vasopressin in controlling acute variceal haemorrhage. BMf 1985; 290: 275-8.

10 Testoni PA, Masci E, Passaretti D, Malesci A, Tittobello A Comin U, et al. Comparison of somatostatin and cimetidine in the treatment of acute bleeding oesophagea varices. Curr Ther Res 1986; 39: 758-66.

11 Bagarini M, Albertini V, Anza M, Barlattani A, Bracci F, et al. Effect of somatostatin in controlling bleeding from oesophageal varices. Ital f Surg Sci 1987; 17: 21-6.

12 Loperfido S, Godena F, Tosolini G, Dematte P, Burei F, Gasparini G, et al. La somatostatina nel traitmento dell emeragia da varici esophago-gastrische. Rec Prog Med 1987; 78: 82-6.

13 Cardona C, Vida F, Balanzo J, Cusso X, Farre A, Guarer C. Efficia terapentica de la somatostatina versus vasopressina mas nitroglycerina en la haemorrhagia actura por varices esophagastricas. Gastroenterol y Hepatol 1989; 12: 19-22.
14 Valenzuela JE, Schubert T, Fogel MR, Strong RM, Levine J, Mills PR, et al. A multicentre randomised double-blind trial of somatostatin in the management of acute haemorrhage from esophageal varices. Hepatology 1989; 10: 958-61.

15 Burroughs AK, McCormick PA, Hughes MD, Springer D, D'Haygere F, McIntyre N, et al. Randomised double-blind placebo-controlled trial of somatostatin for variceal bleeding. Emergency control and prevention of early variceal bleeding. Gastroenterology 1990; 99: 1388-95.

16 Saari A, Klvilaakso E, Inberg M, Paakkonen M, Lahtinen J. Comparison of somatostatin and vasopressin in bleeding oesophageal varices. Am f Gastroenterol 1990; 83: 804-7.

17 Agverinos A, Klonis C, Rekoumis G, Gouma P, Papadimitriou N, Raptis S. A prospective randomised trial comparing somatostatin, balloon tamponade and the combination of both methods in the management of acute variceal haemorrhage. F Hepatol 1991; 13: 78-83.

18 Jaramillo JL, de la Manta M, Mino G, Costan G, Gomez-Comacho F. Somatostatin versus Sengstaken balloon tamponade for primary haemostasis of bleeding oesophageal varices. F Hepatol 1991; 12: 100-5.

19 Shields R, Jenkins SA, Baxter JN, Kingsnorth A, Ellenbogen $\mathrm{S}$, Martin C, et al. A prospective randomised controlled trial comparing the efficacy of somatostatin with injection sclerotherapy in the control of bleeding oesophageal varices. f Hepatol 1992; 16: 128-37.

20 Walker S, Kreichgauer HP, Bode JC. Terlipressin vs somatostatin in bleeding oesophageal varices. A controlled, double-blind study. Hepatology 1992; 15: 1028-30.

21 Hsai HC, Lee FY, Tsai YE. Comparison of somatostatin and vasopressin in the control of acute oesophageal variceal haemorrhage-a randomised controlled study. Chinese $\mathcal{F}$ Gastroenterol 1990; 7: 71-8.

22 Hanisch E, Doertenbach J, Usadel KH. Somatostatin in acute bleeding varices. Pharmacology and rationale for use. Drugs 1992; 44 (suppl): 24-35.

23 Jenkins SA, Baxter JN, Corbett WA, Shields R. Effects of a somatostatin analogue SMS 201-995 on hepatic haemodynamics in the pig and on intravariceal pressure in man. $B r F$ Surg 1985; 72: 1009-12.

24 Navasa M, Bosch J, Chesta J, Bru C, Pizcueta P, Garcia-Pagan JC, et al. Haemodynamic effects of subcutaneous administration of SMS 201-995, a long acting analogue of somatostatin in patients with cirrhosis and portal hypertension [abstract]. f Hepatol 1988; 7 (suppl 1): S64.

25 McCormick PA, Dick R, Siringo S, Wagstaff D, Chesta J, McIntyre N, Burroughs AK. Octreotide reduces azygos blood flow in cirrhotic patients with portal hypertension. Eur 7 Gastroenterol Hepatol 1990; 2: 489-92.

26 McKee R. A study of octreotide in oesophageal varices. Digestion 1990; 45 (suppl): 60-5.

27 Silvain C, Carpentier S, Sautereau S, Fratte JM, Ingrand E, Fort $\mathrm{E}$, et al. A randomised trial of glypressin plus transdermal nitroglycerin versus octreotide in the control of acute mal nitroglycerin versus octreotide in the control

28 Hwang S-J, Lin H-H, Chang C-F, Lee F-Y, Lu C-W, Hsia $\mathrm{H}-\mathrm{C}$, et al. A randomised controlled trial comparing octreotide and vasopressin in the control of acute esophageal variceal bleeding. $\mathcal{F}$ Hepatol 1992; 16: 320-5.

29 Sung JJY, Chung S, Lai C-W, Chan FKL, Leung JWC, Yung $\mathrm{ML}$, et al. Octreotide infusion or emergency sclerotherapy for variceal haemorrhage. Lancet 1993; 342: 637-41.

30 Elsdhoff JD. Surviving proportional hazards. Hepatology 1983; 73: 1631-5

31 Child CG, Turcotte JG. Surgery and portal hypertension. In: Child CG, Dumphy JE, eds. Major problems in clinical surgery: the liver and portal hypertension, Vol. 1. Philadelphia: Saunders, 1964: 1-85

32 Terblanche J, Kahn D, Campbell AH, Jonker MA, Campbell $\mathrm{JH}$, Wright $\mathrm{J}$, et al. Failure of repeated injection sclerotherapy to improve long-term survival after oesophageal variceal bleeding. Lancet 1983; ii: 1328-32.

33 Stiegmann GV, Goff JS, Michaletz-Onody PA, Korolv J, Liebermann D, Saeed ZA, et al. Endoscopic sclerotherapy as compared with endoscopic ligation for bleeding oesophageal varices. $N$ Engl F Med 1992; 326: 1527-32.

34 Laine L, El-Newihi HM, Migikovsky B, Sloane R, Garcia F. Endoscopic ligation compared with sclerotherapy for the treatment of bleeding oesophageal varices. Ann Intern Med 1993; 119: $1-7$.

35 Gimson AES, Ramage JK, Panoz MZ, Hayllar K, Harrison PM, Williams R, et al. Randomised trial of variceal bleeding ligation versus injection sclerotherapy for bleeding oesophageal varices. Lancet 1993; 342: 391-4.

36 Lo G-H, Laik K-H, Chang C-F, Shew M-T, Jeng J-S, Huang R-L, et al. Endoscopic injection sclerotherapy vs. endoscopic variceal ligation in arresting variceal bleeding in patients with advanced hepatocellular carcinoma. F Hepatol 1994; 21 : 1048-52.

37 Howes N, Larman A, Thomas M, Suares S, Jenkins SA, Gilmore IT, et al. High cumulative mortality from recurrent versus first variceal haemorrhage underlines need to prevent rebleeding [abstract]. Gastroenterology 1995; 108 (suppl): A1087.

38 Lin CI, Wei J, Cheng KK, Ho LT. Electropharmacological effects of sandostatin in human atrial fibres. Int $\mathcal{7}$ Cardiol 1991; 31: 313.

39 McCormick PA, Chin J, Greenslade L, Karatapanis S, Dick $\mathrm{R}$, McIntyre N, Burroughs AK. Cardiovascular effects of octreotide in patients with hepatic cirrhosis. Hepatology 1995; 21: 1255-60.

40 Minocha A, Dean HA Jr. Octreotide-induced acute hepatic toxicity. Am f Gastroenterol 1991; 81: 525-6. 
41 Gines A, Salmeron J, Gines P, Jimenez W, Saio J, Piera C, et al. Effects of somatostatin on renal function in cirrhosis Gastroenterology 1992; 103: 1868-74.

42 Mountokalakis T, Kallivretakis N, MayopoulouSymvoulidou D, Karvountzis G, Tulis G. Enhancement of renal function by a long acting somatostatin analogue in patient with decompensated cirrhosis. Nephrol Dial Transplant 1988; 13: 604-7.

43 Carcia-Escribano C, Diez-Marques ML, Gonzales-Rubio M, Rodriguez-Puyol M, Rodriguez-Puyol D. Somatostatin antagonist angiotensin II effects on mesoangial cell contraction and glomerular filtration. Kidney Int 1993; 43: 324-33. 44 Parbhoo S. The management of bleeding in liver disease. $\mathrm{Br}$ f Hosp Med 1975; 15: 17-28.

45 Blavianos P, Gimson AES, Westaby D, Williams R. Balloon tamponade in variceal bleeding; use and misuse. $B M \mathcal{F}$ 1989; 298: 1158 .

46 Westaby D. The management of active variceal bleeding. Intensive Care Med 1988; 14: 100-5.

47 Rector WG Jr. Drug therapy for portal hypertension. Ann Intern Med 1986; 106: 96-107.

48 Gimson AE, Westaby D, Hegarty J, Watson A, Williams R. A randomised trial of vasopressin and vasopressin plus nitro- glycerin in the control of the acute variceal haemorrhage. Hepatology 1986; 6: 410-6.

49 Tsai YT, Lay CT, Lai KH, Lai WW, Ng YS, Yeh JY, et al. Controlled trial of vasopressin plus nitroglycerin in the control of acute variceal haemorrhage. Hepatology 1986; 6: 410-3.

50 Bosch J, Grossman RJ, Garcia Pagnan JC, Teres J, Garcia Tsaao M, Navasa A, et al. Association of transdermal nitroglycerin to vasopressin infusion in the treatment of variceal haemorrhage: a placebo controlled clinical trial. Hepatology 1989; 10: 962-8.

51 Freeman JG, Boden I, Record CO. Controlled trial of terlipressin (glypressin) in the management of acute variceal bleeding. F Clin Gastroenterol 1989; 11: 58-60.

52 Walker S, Stiefel A, Raeosch R, Dommerell S. Terlipressin in bleeding oesophageal varices: a placebo controlled double-blind study. Hepatology 1986; 6: 112-5.

53 Soderlund C, Magnusson I, Torngren S, Lundell L. Terlipressin (triglycyl-lysine vasopressin) controls acute bleeding oesophageal varices: a double-blind, randomised, placebo-controlled trial. Scand f Gastroenterol 1990; 25: 622-30. 